\title{
Model for HR Management in Mining Companies
}

\author{
Assist. Prof. PhD Boryana Trifonova \\ University of Mining and Geology „St. Ivan Rilski “, Sofia, Bulgaria \\ boriana_trifonova@abv.bg
}

\begin{abstract}
According to the accents in the system of managing people in the work process, there are many models for HR management. Dynamic business environment imposes a new look at the role of Human resources in achieving final goals. This is a challenge for leaders of modern organizations. During last years different ideas for new HR management model in mining companies are coming up. This new model emphasizes on the HR value proposition. Management should be directed to benefits for personnel, managers, clients, owners and society. An example for good practice in this direction is the model for management in leading mining companies. HR management via gaining trust with interested sides allows mining companies to succeed in the development and upgrading of their activity during last years. They can also maintain their good public image.
\end{abstract}

Keywords: model for management, human resource, mining companies

JEL Code: A13, M12, O32; doi:10.36997/IJUSV-ESS/2019.8.1.166

\section{Въведение}

Динамичната бизнес среда налага нов поглед към ролята на човешките ресурси при постигане на крайните резултати, което е предизвикателство пред рьководителите на съвременните организации. Те трябва да бъдат гъвкави, да могат бързо да реагират на промените в икономиката, основана на знания, за разлика от предишния модел с основен ресурс капитальт. В същото време, бързите темпове на технологично развитие водят до необходимост от бързо актуализиране на съществуващите към момента компетенции и създаване на нови професии с нови умения, които да бъдат в синхрон с прогреса. (БМГК, 2017). Това предопределя изграждането на стратегически подход към управлението на найценния ресурс на организацията - хората, работещи там, които индивидуално или колективно допринасят за постигане на нейните цели.

Фирмената дейност обективно представлява и изисква обединяване на хора обединяване по начин, който да дава простор пред индивидуалния човешки потенциал, познание и инициативност; обединяване, което да осигурява трайно конкурентно предимство на фирмата именно чрез нейните човешки ресурси; обединяване в трудовата дейност, носещо ползи едновременно за фирмата и за всеки отделен член на персонала. (Илиев, 2005, c.270). Разработените множество модели за управление на човешките ресурси са свързани с т. нар. „твърди“ и „меки“ подходи, прилагани в работата с човешкия капитал. Съвременното акцентиране на интелектуалните активи на организацията, извежда на преден план сборът от знания, умения, мотивация и опит на заетите, лоялност на клиентите, организационна инфраструктура, ефективност на бизнес процесите и др.

\section{1. Теоретичен преглед на модели за управление на човешките ресурси}

Съществуването на множество модели за управление на човешките ресурси се определя от акцентите, които се поставят в системата за управление на хората в трудовия процес. Популярни са следните модели за управление на човешките ресурси:

\section{- Харвардски модел за управление на човешки ресурси}

Доминанта в Харвардския модел са доктрините за човешките отношения и човешката себереализация. В този модел се отделя много голямо внимание на разбирането, че хората могат да оказват съществено влияние върху резултатите от фирмената дейност, особено ако 
са икономически обвързани със собствеността на организацията, в която работят (ако са нейни акционери). Харвардският модел цели изграждането на ефективни отношения между заетите и ръководителите, като поставя акцента върху човешката страна на управлението. Ефективността на управлението на човешките ресурси се отчита съобразно постигнатата ангажираност към предприятието, екипната съгласуваност и фирмената ефективност.

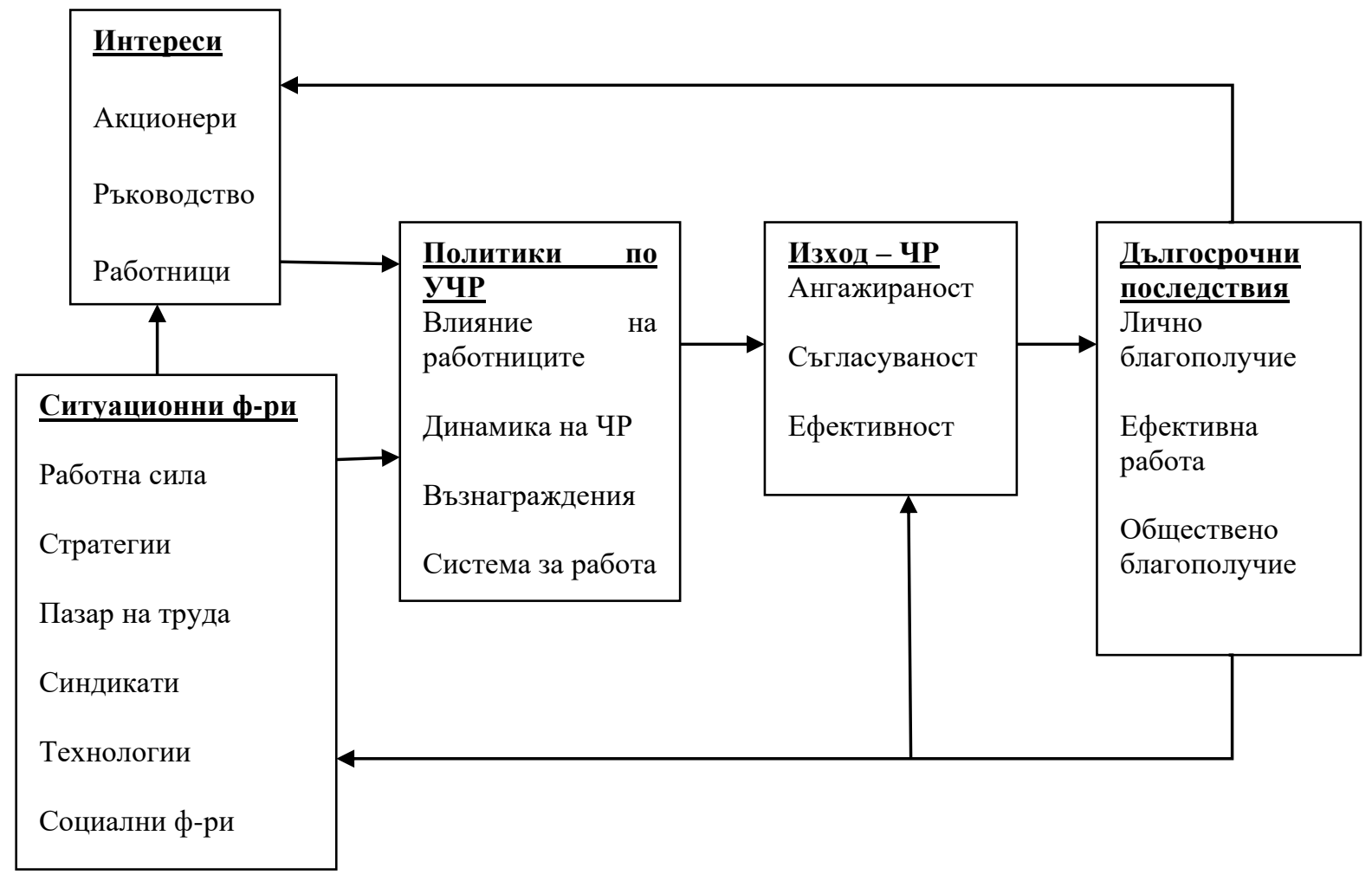

Фигура.1. Харвардски модел на управление на човешките ресурси

М. Армстронг посочва, че Харвардския модел е оказал значително влияние върху теорията и практиката на управление на човешките ресурси, в частност, че управлението на човешките ресурси е дело на всички рьководители, а не само отделна функция на отдела по персонала. (Армстронг, 2005, с.26)

В системно отношение Харвардският модел включва четири основни потока, характеризиращи съдържанието на дейности в управлението на човешките отношения:

Пьрвият основен поток е анализ и проектиране на длъжностите и работните места. Основната цел на този поток е да се постигне максимална удовлетвореност на работниците и служителите от труда, с цел повишаване производителността на труда.

Вторият поток е управлението на трудовите процеси в организацията и по-точно тези на притока от хора - тези, които се вливат, тези, които се движат и тези, които излизат. Оптималният баланс между тези три групи е насочен към постигане на стратегическата цел на организацията, както и нейните икономически цели.

Третият поток е анализ на трудовото възнаграждение. Този анализ има за цел да задържи онези работници и служители, които са необходими за организацията и да се насочат техните усилия към качествено изпълнение на трудовите им задачи.

Четвъртият поток от Харвардският модел е контролиране равнищата на власт, силата и вземането на решенията. При вземането на управленските решения относно човешките ресурси се имат предвид: състояние на трудовия пазар, налични технологии, бизнес цели, нормативна база, интересите на различни групи лица - акционери, мениджъри, общественост. 
В крайна сметка този модел изисква изпълнението на:

- ангажираност на работниците и служителите;

- хармония между елементите на организацията;

- компетентност и изпълнение на поставените им задачи;

- икономическа ефективност от дейността на организацията.

- Модел на Мичиганската бизнес школа за управление на човешки ресурси

На другият полюс стои Мичиганския модел. Той е разработен в Мичиганската бизнес школа от К. Фомбран, Н. Тичи и М. Девана. В него доминира разбирането, че човешките ресурси не се различават от останалите ресурси. Поради това, след като не се различават от машините, сградите, материалите и суровините, човешките ресурси трябва да се управляват както другите ресурси. На тази база Мичиганският модел акцентира върху икономическата страна на управлението на хората в трудовия процес и възприема четири основни постулата:

- цената на работната сила трябва да бъде приемлива за организацията;

- работниците и служителите трябва да бъдат използвани така, за да може тя да извлече най-голяма полза от тях;

- инвестициите в човешкия капитал и развитието на персонала трябва да отговаря на потребностите на организацията и да й носят определена икономическа изгода;

- работниците и служителите в организацията трябва да бъдат поставени при такива условия, за да се постигне максималната им ангажираност и да се постигне пълноценна и ефективна реализация на техните възможности.

Както посочва М. Армстронг „този подход изхожда от философия, ориентирана към интересите на предприятието, той поставя акцент върху необходимостта да се управляват хората, така че да се получи от тях добавена стойност и по такъв начин да се постигне конкурентно преимущество. Този подход разглежда хората в качеството им на човешки капитал, от който при разумни инвестиции в неговото развитие може да бъде получен доход.“(Армстронг, 2005, с.22)

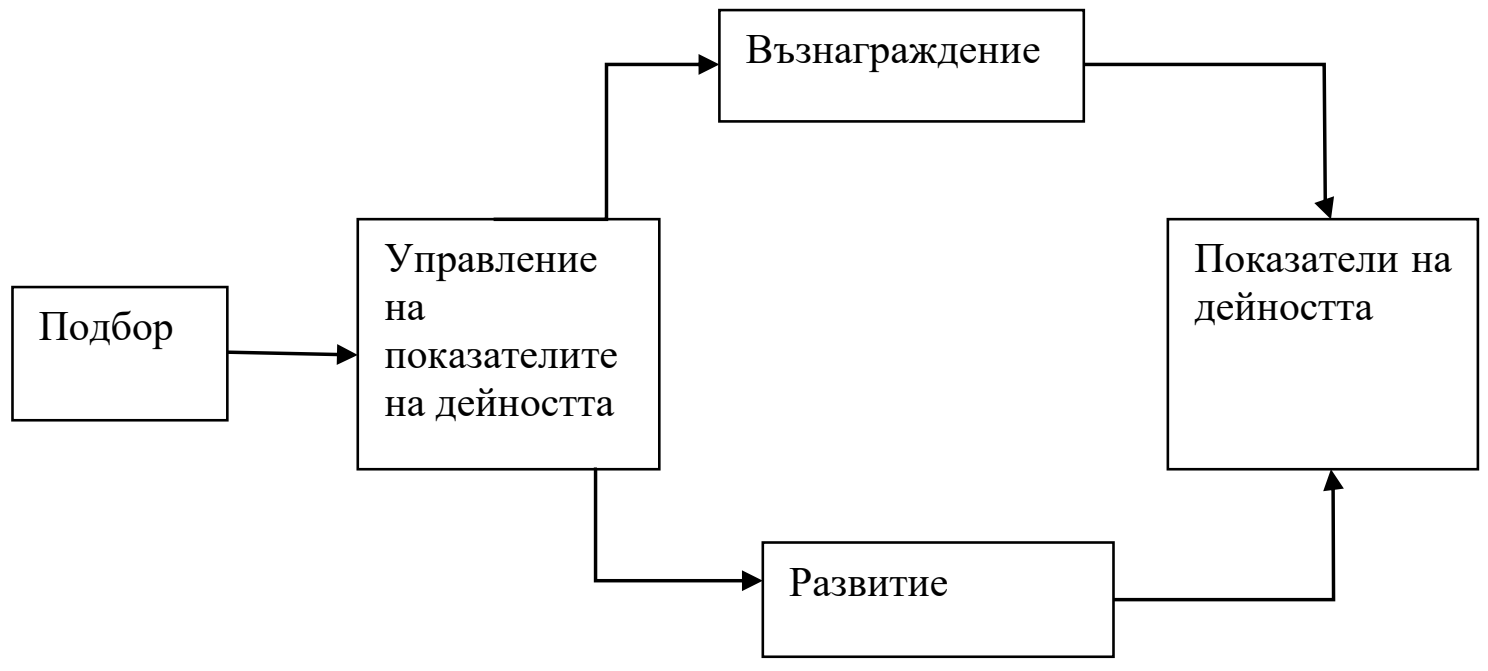

Фигура. 2. Мичигански модел на управление на човешките ресурси

И двата модела /Харвардският модел и Мичиганският модел/ не се отричат взаимно, въпреки привидните различия в тях. Харвардският модел акцентира на човешката страна. Мичиганският модел не отрича използването на човешките отношения и на човешките потребности. 


\section{- Модел на Гест за управление на човешки ресурси}

Този модел се основава на разбирането, че насоката на управлението на човешките ресурси е да се постигне максимално възможна ангажираност на работниците и служителите при изпълняваните задачи. Очакваният резултат е припокриване между целите на организацията и индивидуалните цели, както и тяхната интеграция в работния процес. На следващо място - работниците и служителите да отдадат своите сили и възможности за успехите на организацията.

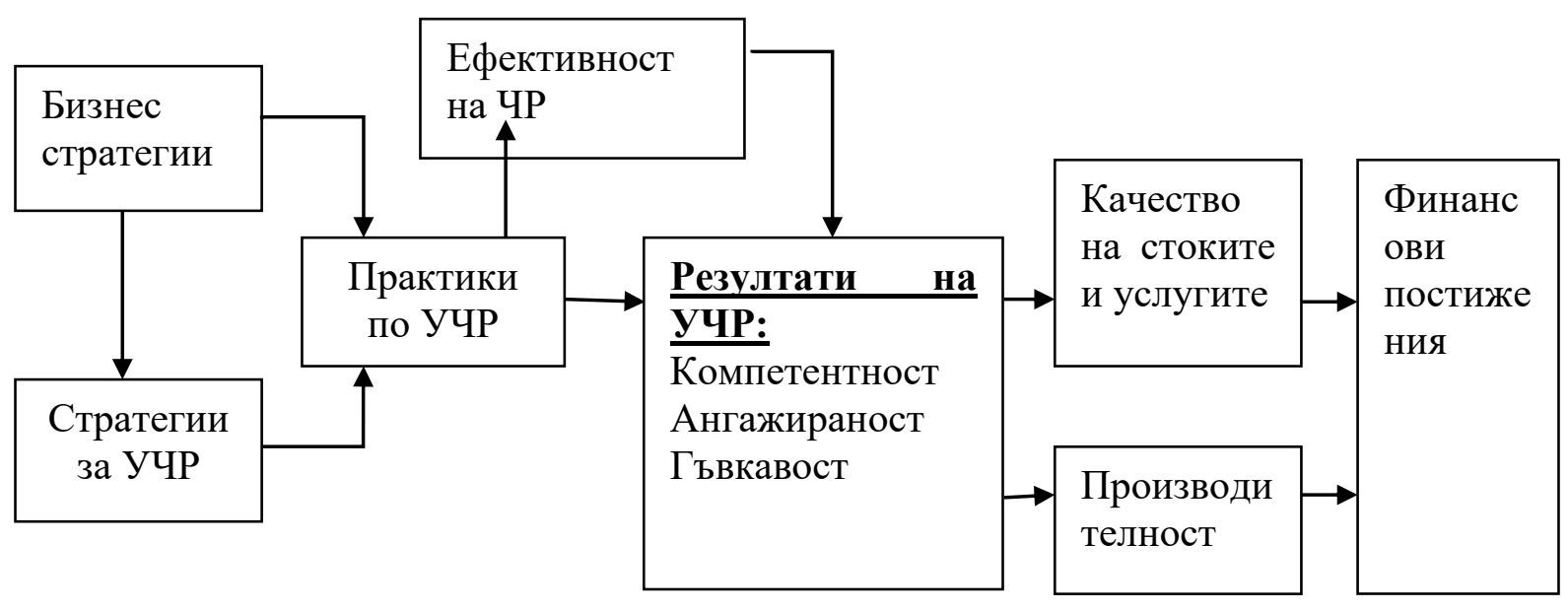

Фигура. 3. Модел на Гест за управление на човешките ресурси

Моделът на Дейвид Гест е базиран върху четири стратегически цели: (Армстронг, 2005, c.27)

- стратегическа интеграция - свързана е с възможността въпросите за управление на човешките ресурси да се интегрират във всички стратегически планове, позволявайки на рьководителите на средни нива да отчитат перспективите при вземане на решение относно човешките ресурси;

- висока ангажираност - включва поведенческа ангажираност и позитивна ангажираност, необходими за идентифициране на индивидуалните с организационните цели;

- високо качество - доказана е връзката: поведение на ръководителите-качество на стоките и услугите, дори за наемането на качествен персонал;

- гъвкавост - функционалната гъвкавост и наличието на адаптивна организационна структура позволяват на предприятието да се справя с нововъведенията.

- Модел „Управление на човешките ресурси, което създава „стойност”

През последните години се представят и прилагат различни идеи за нов модел за управление на човешките ресурси. Един от най-популярните в тази насока е създаден от Ulrich и Brockbank под името „Управление на човешките ресурси, което създава стойност“. Те считат, че „Управление на човешките ресурси, което добавя „стойност” създава усещане за полза и ценност в съзнанието на определени групи от хора - това са потребители, служители, мениджъри и акционери на бизнеса на компанията, като с това им помага да постигнат и своите конкретни цели.“ (Ulrich, D.,W. Brockbank. 2005, p.26) Техният модел включва пет, взаимосвързани елемента, които са изобразени на фигура 4. 


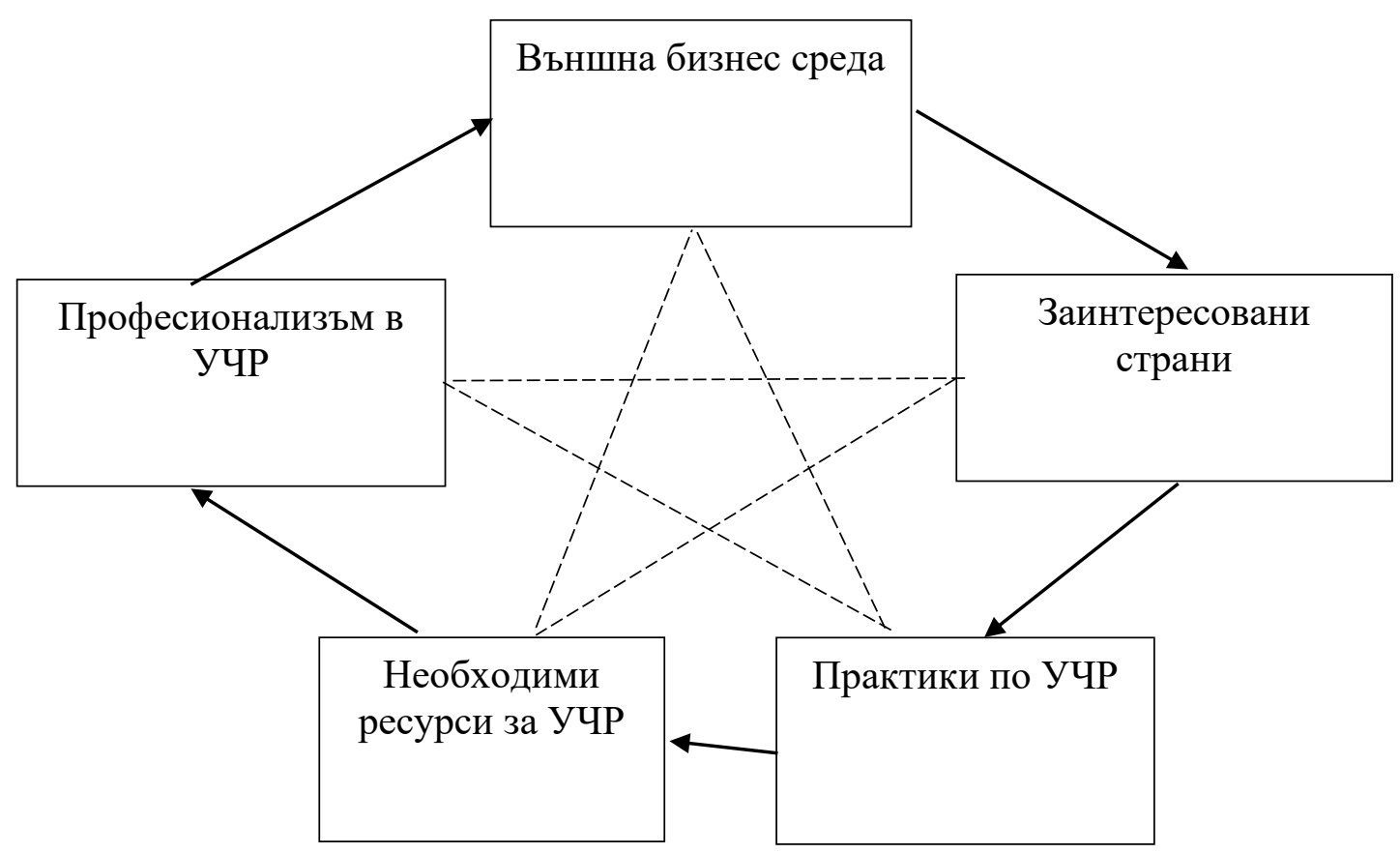

Фигура. 4. Модел на Ulrich и Brockbank за управление на човешките ресурси

Основната идея е дейностите по управление на човешките ресурси да генерират „стойност“, т.е. ползи за персонала, мениджърите, клиентите, инвеститорите и собствениците. Според авторите за постигането на нужните промени от прилагането на този модел е необходимо последователно да се изпълняват петте елемента като се започне от проучване на външната бизнес среда и движението се извършва по плътните линии. Но може вместо тях да се следват пунктираните линии или да се започне от оценка на компетентността на персонала, инвестицията в ресурси или друг елемент. Задължително условие при приложение на модела е интегрираното изпълнение и на петте елемента. Елементите съдържат:

- отлично познаване на външната бизнес среда, която включва познаване на новостите в технологиите, икономическата среда, законовите регулации, демографската криза, наложилата се глобализация;

- отлично познаване на нуждите на заинтересованите страни - персонала, мениджърите, клиентите, инвеститорите и собствениците;

- прилагане на действени управленски практики по управление на човешките ресурси в следните насоки: свързани с движението на хората и задържане на таланта, свързани с изпълнението на задачите, оценка на изпълнението и полученото възнаграждение, свързани с анализа на длъжностите, свързани с изграждане на комуникационната стратегия в организацията;

- осигуряване на необходимите ресурси за постигане на желаните резултати - дава се възможност на организацията да обвърже управленските практики по управление на човешките ресурси с изпълнение на бизнес стратегията;

- осигуряване на висок професионализъм в управлението на човешките ресурси, което изисква постоянно усъвършенстване на компетентността на всички мениджъри в организацията.

В управлението на човешките ресурси е от голямо значение да се съсредоточи повече върху това, което предлага като ползи за външната среда и заинтересованите страни. Това трябва да се извърши чрез вътрешни промени в управленските практики, осигуряване на необходимите ресурси и развитие на управленския професионализъм в рамките на организацията. 


\section{2. Добри практики в управлението на човешките ресурси в добивните предприятия}

Предприятията от добивната промишленост в България са обединени от идеята да работят, спазвайки Стандарт за устойчиво развитие в бранша (приет на Международна бизнес конференция в гр. Пловдив, 2012г. от 150 специалисти от минния сектор от 14 европейски държави, БМГК и Министъра на икономиката, енергетика и туризма). Десет са основните принципи в този Стандарт, по-важните от които са:

- Осигуряване здравето и безопасността на всички свои служители и сътрудници;

- Повишаване професионалната удовлетвореност и стандарта на живот на своите служители и минните общности;

- Инвестиране в устойчивото развитие на местните общности.

Основната цел, около която се обединяват предприятията от бранша, е да се осигурят безопасни работни места, справедливо и достойно заплащане на труда и устойчиво развитие на регионите, в които е съсредоточена добивната индустрия.

\section{- Инвестиции в безопасни работни места}

В бранш, където рискът за безопасността при работа е огромен, натоварванията също, превръщането на грижата към човешките ресурси в ценност е не само задължително, но и подпомагащо конкурентоспособността на тези компании. Не случайно водещите добивни предприятия изграждат политики, процедури, инвестират в безопасни работни места и обучение на персонала, насочени към изграждане на отговорно поведение на всеки работещ. Постигнатите високи икономически резултати са свързани със значителните капиталови инвестиции в съвременни технологии и с инвестициите в повишаване на квалификацията на заетите (Гъльбова, Несторов, 2019).

Във водещите компании от този бранш от 2014г. е внедрена интегрирана система за безопасност, която включва видеонаблюдение, контрол на достъпа и пожароизвестяване. Ефектьт от баланса между технология и човешки фактор е постигната превенция на злополуките на работното място. Полезността на системата относно безопасността е заложената възможност да се сигнализира за опасности, да се регулира трафика и скоростта на движение, дори подобрено движение при ограничена видимост. Дори се увеличава нейният обхват като събраните данни са налични 24 часа в денонощието за инженернотехническия персонал, не само на персоналните им компютри, но и на мобилните им телефони, което е водещо при вземането на аргументирани решения.

Друг пример за добра практика в тази насока е въвеждането на „златни правила““ за осигуряване на по-сигурна и безопасна работна среда. Те трябва да се спазват от всеки, който извършва някаква дейност на територията на предприятието. Внедрена е процедура за „Здраве и безопасност“ с цел непрекъснато подобряване на условията на труд. Тя включва прилагане на добри практики, контрол на факторите на работната среда и производствения процес, оценка на риска, правилно използване на ЛПС, превенция на трудовите злополуки, инциденти и професионални заболявания.

Сред постоянните мерки за подобряване на здравето и безопасността при работа са доставката на нови машини и съорьжения, включващи най-високите световни норми по безопасност, както и стриктния контрол по изпълнение на правилата. Освен техническата въоръженост, за подобряване на производителността на труда при извличане на подземни богатства е разработен и се използва комплексен софтуер. Чрез него се създава геоложки 3D модел на съдържащите се компоненти на подземното богатство и се намират оптимални решения за експлоатация на находищата. В резултат на системната управленска политика се отчита нулев трудов травматизъм и липса на професионални заболявания.

- Инвестиции в развитие на човешките ресурси

Добивната промишленост се отличава с благоприятна среда за иновации и с капацитет 
за внедряване на високотехнологични производства, а така също и с относително висока ефективност на използваните ресурси (Гълъбова, Несторов, 2019). БМГК в стремежа си да бъде в крак с времето създаде браншови модел за подготовка на кадри, чиято цел е покриване на недостига от специалисти и осигуряване на качествено образование за бъдещите кадри в бранша. (БМГК, 2019). Една от основните цели, които си поставят предприятията от бранша е предоставяне на най-различни възможности на персонала за придобиване на нови знания, за развиване на лидерски умения, професионални и технически качества. Обрьща се внимание на взаимоотношенията с човешките ресурси и синдикатите, като на тази основа е постигнат постоянен диалог чрез разработената корпоративна политика за полагане на достоен труд. Прилагат се процедури за подаване на оплаквания при нередности от трудово-правен характер или нарушени човешки права.

В отрасъла се реализира проект „Да работим заедно“, който включва обучение на всички служители за вземане на решения, работа в екип, бърза реакция в различни случаи. Неговата цел е повишаване ангажираността и неизползвания потенциал на служителите, както и изграждане на желаната организационна култура. Обученията на екипите са в посока да дават най-доброто от себе си, да насьрчават креативността им, което води до подобрение на производителността и представянето на компаниите.

Друг поглед върху осъществяването на комуникация в добивно предприятие на принципа създаване на ценности предлага създадена интранет-платформа с разнообразни възможности. Тук освен, че се предоставя актуална информация за конкретно предприятие, заедно с презентации на различните дейности, е възможно публикуването на лични обяви за търсене и предлагане. Така създадената платформа насърчава социалната комуникация между служителите, както и възможността за информираност на обществеността. Интранетьт позволява провеждането на кратки анкети и гласуване сред служителите. По този начин те участват пълноценно в дейността на предприятието, виждайки, че гласът им има значение и може да бъде взет под внимание. На практика това прави процесът на вземане на решение отворен за всеки служител, а приносът му оценен от страна на мениджмънта.

\section{- Инвестиции в местни общности}

Пример за създаване на комуникации с местните общности е поддържането на постоянни информационни центрове за граждани в гр. Пирдоп и гр. Златица. Те работят от 2011 г. с цел информиране на местното население по всички въпроси, свързани с дейността на предприятията от добивната промишленост. Такива въпроси са различните аспекти на опазването на околната среда, възможностите за откриване на нови работни места, корпоративната социална отговорност и различните мероприятия, свързани с нея. В тези центрове също се организират регулярни срещи на местното население с мениджъри и специалисти, на които се обсъждат обществени проблеми и приоритети за партньорството между община и предприятие.

В основата на идеята за създаване на индустриални клъстери е концепцията за споделената стойност. Според нея пазарите се развиват не само от нуждите на корпорациите, но и от нуждите на обществото. Само когато бизнесът инвестира и в създаването на ценности се постига дългосрочна, устойчива и конкурентоспособна икономическа стойност. Както обществото се нуждае от успешен бизнес, така и бизнесът се нуждае от успешно общество. Не само от гледна точка тьрсене на продукти и услуги, но и за осигуряване на ключови публични активи, благоприятна и устойчива обкръжаваща среда.

Предприятията от клъстер в бранша провеждат ежегодни дни на отворени врати, на които представят свои проекти и инициативи за подобряване на инфраструктурата, здравеопазването, образованието, развитието на културата и спорта в общините, където са разположени. Акцент в работата им са инвестициите в безопасни работни места, в обучение и квалификация на човешките ресурси, както и усилията за по-чиста околна среда. Чрез 
„споделени ценности“ се създават условия за просперитет на отрасъла, за ефективно и разумно използване на природните ресурси и защита на обществения интерес. Придържането към високи етични стандарти и бизнес практики дават възможност за повишаване на ефективността на труда, за подобряване на взаимоотношенията със заинтересованите страни, за постигане на доверие в обществото към този бранш.

\section{Заключение}

Управлението на човешките ресурси е от голямо значение да се съсредоточи повече върху това, което предлага като ползи за външната среда и заинтересованите страни. Това трябва да се извърши чрез вътрешни промени в управленските практики, осигуряване на необходимите ресурси и развитие на управленския професионализъм в рамките на организацията. Наличието на удовлетворени работници може да бъде основа за създаване на „привлекателно място за работа“, което води до удовлетвореност и запазване на клиентите (привлекателно място за купуване). Това от своя страна може да превърне компанията в „привлекателно място за инвестиране“, защото влияе върху възвръщаемостта на инвестициите и ръста на приходите. (Атанасова, 2015, с.144)

Съвременният модел за управление на човешките ресурси следва да е насочен към получаване на ползи за персонала, мениджърите, клиентите, собствениците и обществеността. Пример за добра практика в тази насока е управленския модел във водещи предприятия от добивната промишленост. Управлението на човешките ресурси чрез изграждане на доверие с различните заинтересовани страни позволява на добивните компании да успяват в последните години да развиват и надграждат своята дейност и да поддържат добър имидж пред обществеността.

\section{References}

1. Armstrong, M. (2005) Upravlenie na choveshkite resursi, Delfin Pres, B.

2. Atanasova, M., (2015) Management na choveshkite resursi - Teoria i praktika, Avangard Prima, $\mathrm{S}$.

3. Aurubis-Bulgaria, https://bulgaria.aurubis.com/bg/

4. BMGK, Analis na sastoyanieto na kadrovoto osiguryavane v sector "Dobivna promishlenost" i predlogenie za sazdavane na branshova sistema za podgotovka na kadri, available at: http://www.bmgk-bg.org/content/fm/14/1045/ AnalizKadri5_final_3.pdf (accessed 08 June 2017.)

5. BMGK, (2019) Mineralno-surovinnata indusria v Bulgaria, Annual newsletter.

6. Dundee Precious Metals, https://dundeeprecious.com/

7. Galabova, B., N. Nestorov. (2019) Rolq na dobivnata promishlenost za balgarskata ikonomika. Minno delo i geologiq, vol. 5/2019, pp. 18-24.

8. Harizanova, M., D. Boyadjiev, N. Mironova, (2006) Upravlenie na choveshkite resursi UNSS, S.

9. Iliev, Y.(2005) Upravlenie na choveshkite resursi. Umenieto da motivirame, Abagar, V. Tarnovo.

10. Industrial Cluster Srednogorie, https://srednogorie.eu/

11. Shopov, D., D. Kamenov, M. Atanasova, G. Evgeniev, Y. Bliznakov, (2013) Kak da upravlyavame choveshkite resursi v predpiyatieto, IK Trud i pravo.

12. Trifonova, B. (2018) Upravlenie na choveshkite resursi, Avangard - Prima, S.

13. Trifonova, B. „Shared Values "as a model of building stable work environment in the company, Science \& Research, volume 2, 2018, Number 2, Social Studies, Journal of the Union of Scientists - Stara Zagora, pp.27-30

14. Ulrich, D., W. Brockbank, (2005) The HR Value Proposition, Harvard Business Press 